\title{
Discrepancies between ecological and individual data on fruit and vegetable consumption in fifteen countries
}

\author{
Joceline Pomerleau*, Karen Lock and Martin McKee \\ European Centre on Health of Societies in Transition, London School of Hygiene and Tropical Medicine, \\ Keppel Street, London WC1E 7HT, UK
}

(Received 17 April 2002 - Revised 16 December 2002 - Accepted 9 January 2003)

\begin{abstract}
Although food supply statistics are commonly used in ecological studies of diet and disease, little information is available on how they compare with reported intakes of foods. The objective of the present study was to compare fruit and vegetable availability with estimates of national mean intakes derived from national food consumption surveys. Food availability statistics from the FAO were used. For each country, mean national supply, based on at least 3 years of FAO data, was calculated. National estimates of mean fruit and vegetable intakes were derived from population-based surveys from fifteen countries, gathered for the World Health Organization Global Burden of Disease Study revision for 2000. Extrapolations were made when survey data did not cover all age groups. For each country, the FAO:survey estimate ratio was calculated. This ratio ranged from 0.93 to 2.70 (median value $=1.39$ ). Although there was a tendency for FAO data to overestimate intakes (fourteen out of fifteen countries), the degree of overestimation varied greatly among the countries included in this study $(5-270 \%)$. As food supply statistics are the only source of information on dietary patterns in most countries of the world, further information on how they reflect food intakes is needed. Obtaining detailed and valid estimates of dietary intakes in more countries around the world will be essential for such comparisons.
\end{abstract}

Fruits: Vegetables: Food supply: Diet surveys: Epidemiologic studies

Despite the increasing importance of nutrition in integrated policy initiatives to tackle the rise in non-communicable diseases worldwide (World Health Organization, 2002a), a large amount of the existing evidence for the role of dietary intake in explaining worldwide differences in mortality and disease incidence is based on ecological information, with food availability being used as a proxy for dietary intake. Availability data predominantly come from food balance sheet data from the FAO (Food and Agriculture Organization, 2001), although results from household budget surveys are increasingly used (Lagiou et al. 1999). Food balance equates to the production of food in a country plus imports (adjusted for changes in stocks), and minus exports, foods lost in storage, transport and processing, fed to livestock and used for seeds and or for non-dietary purposes.

While differences in dietary patterns among regions and countries are acknowledged, assessing the level of these differences represents a major challenge for researchers.
Nationally representative surveys of dietary intake are performed only in a limited number of countries and the diversity of the methods used makes comparisons difficult. In addition, when the objective of the survey is to measure individuals' actual food and nutrient intakes, the validity of the data is highly influenced by the ability and willingness of the respondents to provide accurate information on their intake, and by the fact that the procedure involved in measuring dietary intake may lead to changes in behaviour (Bingham et al. 1988; Willett, 1998a).

While it is generally acknowledged that food balance sheets tend to overestimate dietary intakes in developed countries and possibly underestimate intakes in less developed countries (Statistics Division, 1983; Food and Agriculture Organization, 1998a,b; Joffe \& Robertson, 2001), little information is available on the magnitude of the discrepancy between food supply data and information from dietary surveys of individual intakes with regards to various types of foods.

\footnotetext{
Abbreviation: GBD, Global Burden of Disease.

* Corresponding author: Dr Joceline Pomerleau, present address 8 Rue de Rémusat, Paris 75016, France, fax +33 145201671 , email Joceline.Pomerleau@1shtm.ac.uk
} 
One food group currently under epidemiological scrutiny is fruits and vegetables. Accumulating international epidemiological evidence has suggested that increased dietary fruits and vegetables could reduce the risk of major disorders such as cardiovascular diseases and certain cancers, thus reducing premature deaths (World Cancer Research Fund \& American Institute of Cancer, 1997; Klerk et al. 1998). The consistency of these findings has led several national and international bodies to advocate an increase in intake to at least $400 \mathrm{~g} / \mathrm{d}$ (World Health Organization, 1990; World Cancer Research Fund \& American Institute of Cancer, 1997) and WHO has recently assessed the contribution of low fruit and vegetable consumption to the worldwide burden of disease in its update of the Global Burden of Disease (GBD) study (World Health Organization 2002b).

Within the framework of the WHO GBD study revision, data on patterns of intake of fruits and vegetables in countries around the world have recently been collected. Because data collation at the international level is rare, it was decided to use the information available in an attempt to estimate variations in the magnitude of the discrepancy between national availability of fruits and vegetables (FAO food balance sheet data) and national estimates of fruit and vegetable intakes derived from individual food consumption surveys.

\section{Experimental methods}

Sources of information on fruit and vegetable consumption

National availability of fruits and vegetables: FAO food balance sheets. Country-specific data on per capita availability of fruits (excluding wine; FAO code 2919) and vegetables (FAO code 2918) were downloaded from the FAOSTAT database on the FAO internet website (Food and Agriculture Organization, 2002). FAO data from 1980 until 2000 (last year available) were used. For each country included in the analyses (see Table 1), an average fruit and vegetable supply, based on at least 3 years of FAO data (around the data collection period), was calculated in order to reduce the effect of annual variations in availability data. Years were chosen to cover, as much as possible, the surveys' respective data collection periods. Data for Belgium were based on the FAO estimates provided for Belgium and Luxembourg combined.

National estimates of fruit and vegetable intake: data collated for the WHO Global Burden of Disease study. The estimates of intakes used in the present paper were based on data collated for the GBD study revision (Ezzati et al. 2002). The input data required in the GBD study to calculate the worldwide disease burden attributable to low fruit and vegetable intake included estimates of national mean fruit and vegetable intake stratified by pre-specified age groups $(0-4,5-14,15-29,30-44$, $45-59,60-69,70-79, \geqslant 80$ years) from countries around the world. Studies of individual dietary intake were identified using a comprehensive search, which included computerized databases of published articles and library catalogues, hand-searching of bibliographies, internet searches, and extensive contacts with experts in the field, national governments and non-governmental organisations (Lock et al. 2003). Studies were selected if they were recent (from 1980), the sample was large (sample size calculations ideally included) and as representative as possible of the reference population (covering the whole country and not only one region), most age groups were surveyed, non-response was ideally documented, the methods used to collect data were as free of bias as possible, statistical analysis of the data was appropriate, and data were available as fruits and vegetables g/d. Only population-based cross-sectional studies, baseline assessment of large cohort studies or large interventions (sample representative of the general population) were considered for inclusion. Estimates had to exclude potatoes, pulses and starchy vegetables and fruits in order to be consistent with current international recommendations (World Cancer Research Fund \& American Institute of Cancer Research, 1997); they included fruit and vegetable juices.

Data were obtained for twenty-six countries (Lock et al. 2003), but it was decided to keep in the current analyses only data from studies that met the following criteria: (1) FAO data for the country were available; (2) information on sampling strategy was available; (3) estimates were provided for males and females separately; (4) estimates did not exclude fruit juices; (5) data were collected using $24 \mathrm{~h}$ recalls or food diaries, as these provide better estimates of absolute intakes than food-frequency questionnaires (Willett, 1998a); (6) estimates were provided directly by the survey investigators using the GBD age-grouping.

After exclusions, a total of fifteen studies were retained for analysis. Table 1 provides methodological information on the surveys. Further details have been published elsewhere (Andersen et al. 1996; National Institute of Nutrition of Kazakhstan \& Macro International Inc., 1996; Tippett \& Cypel, 1997; Findiet Study Group, 1998; Petrova et al. 1998; Australian Bureau of Statistics, 1999; De Henauw \& De Backer, 1999; Turrini et al. 1999, 2001; Ministry of Health and Welfare, 2000; Pomerleau et al. 2000; Mizushima, 2001; Carolina Population Center at the University of North Carolina at Chapel Hill, 2001, 2002; Du et al. 2002; N Kaluski and R Goldberg, personal communication). Only one study was from the 1980s. Sample sizes ranged from about 2000 to 22000 subjects. The studies attempted to provide nationally representative samples, most using multi-stage random sampling and all excluding institutionalized individuals.

Because several surveys did not include children or the elderly, indirect estimations and extrapolations were made to obtain estimates of national intakes. When data were unavailable for children, extrapolations were on the basis of two sources of information: (1) estimates of fruit and vegetable intakes obtained from other surveys collected for the GBD study suggest that boys and girls aged 5-14 years and those aged $0-4$ years consume 20 and $45 \%$ less fruits and vegetables respectively than adults aged 30-59 years; (2) published estimates of energy requirements (Food and Agriculture Organization/World Health Organisation/United Nations University, 1985) suggest that girls and boys aged $5-14$ years require approximately 15 and $20 \%$ less dietary energy than adult women and men respectively, values for 


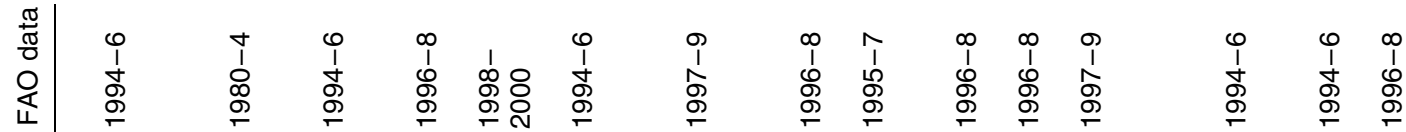

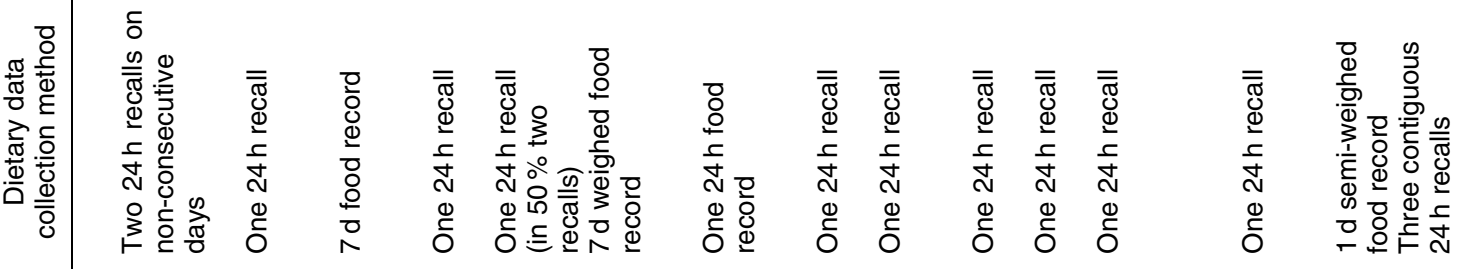

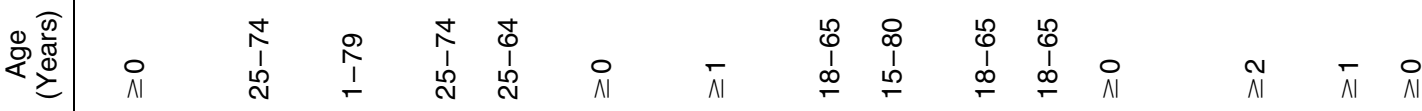

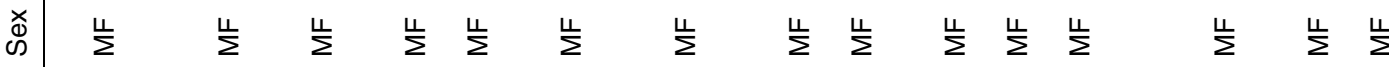

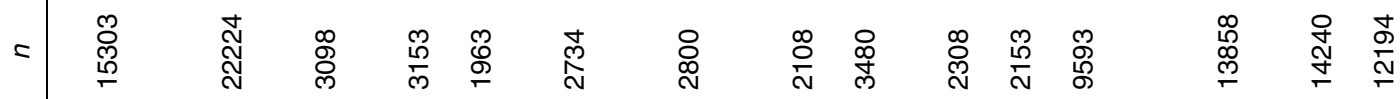

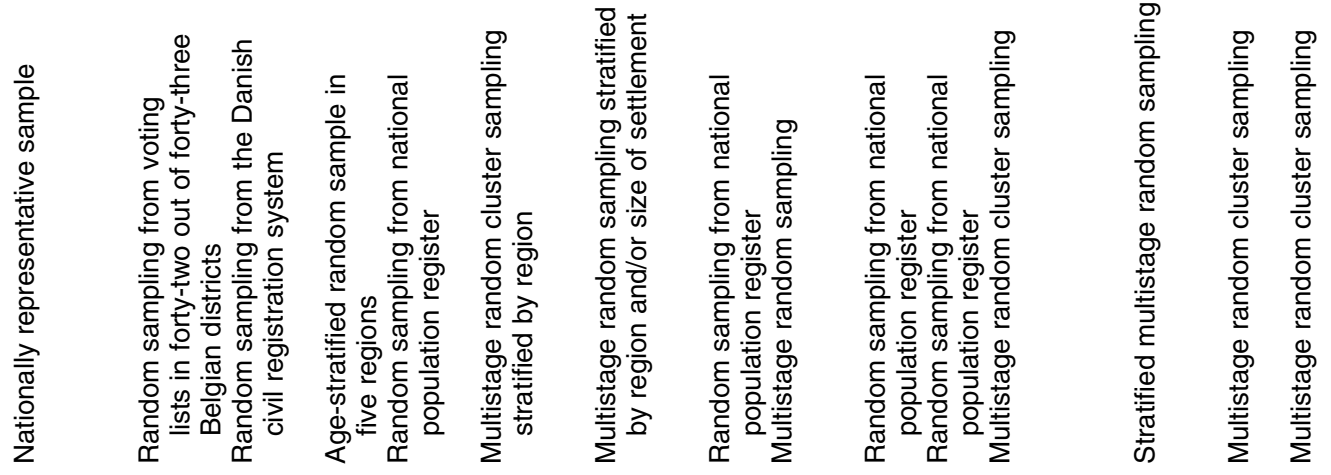

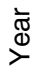

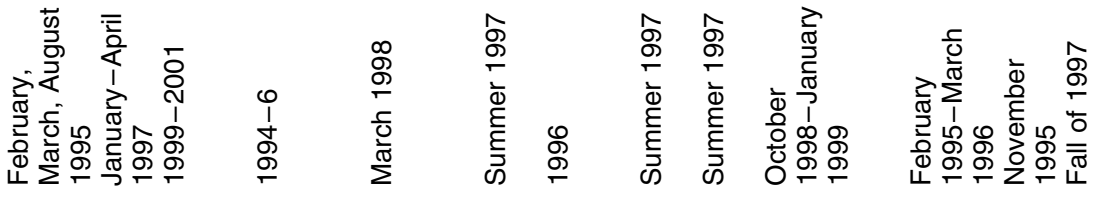

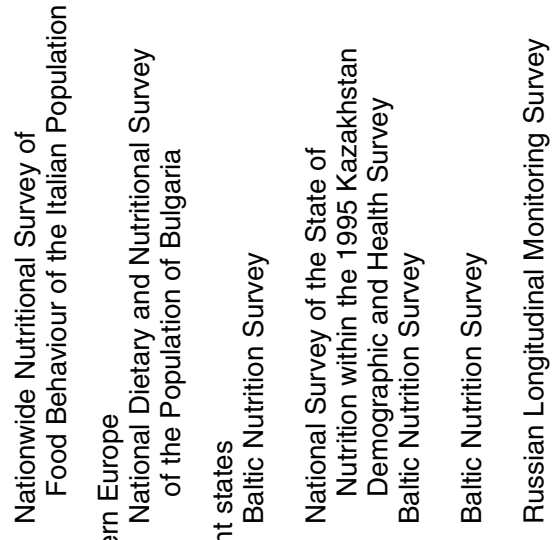

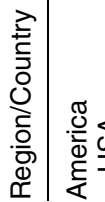

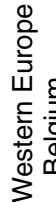

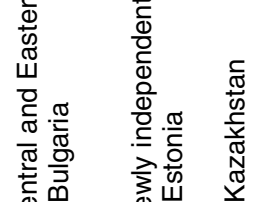

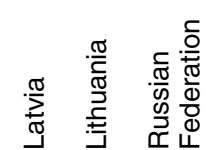

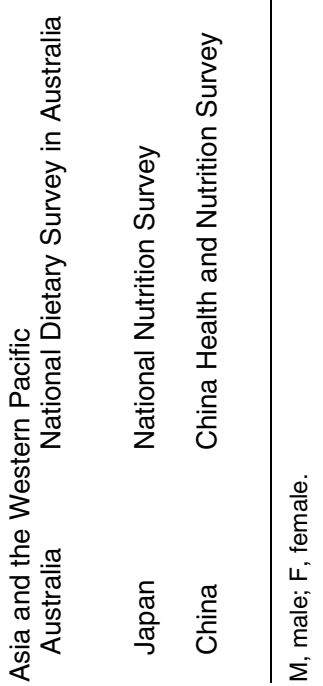


girls and boys aged $0-4$ years are about 40 and $50 \%$ less than adults of the same gender respectively (these estimates may, however, vary among countries and they will depend on the true energy expenditure of the children). As the two sources of information tend to agree, the following adjustment factors were used: (1) 5-14 years: $20 \%$ lower fruit and vegetable intake than adults aged 30-59 years; (2) $0-4$ years: $45 \%$ lower intake than adults aged 30-59. When survey results were unavailable for the elderly, a similar approach was used: (1) information on fruit and vegetable intakes from survey data suggest that men and women aged 70-79 years consume approximately the same amount of fruits and vegetables per d, on average, as their counterparts aged 30-59 years, while individuals aged $\geqslant 80$ years consume approximately $10 \%$ less fruits and vegetables than middle-aged adults; (2) values based on energy requirements suggest that men and women in older age groups consume approximately $10-15 \%$ less energy than middle-aged adults. Thus, the following assumptions were made: (1) 70-79 years: same intake as adults aged $60-69$ years; $(2) \geqslant 80$ years: lowest estimate obtained from the following two options: $10 \%$ lower intake than adults aged $30-59$ or same amount as adults aged $70-79$ years.

Once estimates of intakes were obtained for all the required categories of gender and age (see earlier), national population weighed (Department of Economic and Social Affairs, 1998) mean fruit and vegetable intakes were derived. These were used in the analyses described in the present paper.

\section{Statistical analyses}

Comparisons between national availability of fruits and vegetables and national estimates of mean fruit and vegetable intake based on survey data were made using the statistical package Stata (version 6; Stata Corporation, College Station, TX, USA). The FAO:survey data ratio was calculated. A value $>1$ suggests that FAO data tend to overestimate population intakes while a value $<1$ suggests that FAO data tend to underestimate population intakes. Countries were grouped by geographical region. Israel was included with western European countries to parallel the usual WHO country classification.

\section{Results}

The comparison of FAO and survey data is presented in Table 2. The ratio of fruit and vegetable supply to the estimated mean national fruit and vegetable intake, ranges from 0.93 to 2.70 (median 1.39). In all countries but Finland fruit and vegetable availability is higher than mean national intake (ratios ranging from 1.05 to 2.70 ). The median overestimation level is $46 \%$.

Examining within-region variations in the level of discrepancy between FAO and survey data is possible for western Europe and countries of the former Soviet Union as data from five countries are available for each of these regions. The range of discrepancies among countries is very large in the western European group. FAO data appear to slightly underestimate individual intakes in Finland, but they overestimate intakes in the other countries by between $36 \%$ (Belgium) and $270 \%$ (Israel). In countries of the former Soviet Union, per capita fruit and vegetable supply is higher than the estimated mean intakes in all five countries included in the comparisons. Although the range of discrepancies is much smaller in that region than in the western European group, betweencountry variations exist. While the level of overestimation is $15 \%$ or less in two countries (Estonia $5 \%$, Kazakhstan $12 \%$ ), it reaches $21 \%$ in Lithuania, $38 \%$ in Latvia and $52 \%$ in the Russian Federation.

Finally, when data from the most economically developed countries (USA, western Europe, Australia, Japan) were considered, the median FAO:survey ratio was 1.51 .

Table 2. Estimates of fruit and vegetable availability (FAO data) and intake (survey data) and FAO:survey estimates ratios, by region and country*

\begin{tabular}{|c|c|c|c|c|}
\hline WHO region & Country & FAO data ( $g /$ person per $\mathrm{d}$ ) & Survey data (g/person per $d)$ & FAO:survey ratio \\
\hline America & USA & 656 & 288 & $2 \cdot 28$ \\
\hline \multirow[t]{5}{*}{ Western Europe and Israel } & Belgium & 465 & 342 & 1.36 \\
\hline & Denmark & 419 & 259 & 1.62 \\
\hline & Finland & 381 & 408 & 0.93 \\
\hline & Israel & 1022 & 379 & $2 \cdot 70$ \\
\hline & Italy & 824 & 435 & 1.89 \\
\hline Central and Eastern Europe & Bulgaria & 533 & 351 & 1.52 \\
\hline \multirow[t]{5}{*}{ Former Soviet Union } & Estonia & 340 & 325 & 1.05 \\
\hline & Kazakhstan & 168 & 150 & $1 \cdot 12$ \\
\hline & Latvia & 344 & 250 & 1.38 \\
\hline & Lithuania & 402 & 331 & $1 \cdot 21$ \\
\hline & Russia & 319 & 210 & 1.52 \\
\hline \multirow[t]{3}{*}{ Asia and Western Pacific } & Australia & 479 & 344 & 1.39 \\
\hline & China & 572 & 313 & 1.83 \\
\hline & Japan & 454 & 413 & $1 \cdot 10$ \\
\hline
\end{tabular}

\footnotetext{
${ }^{*}$ For details of procedures, see p. 828
} 
However, this summary value hides large between-country variations.

\section{Discussion}

FAO food balance sheets are a widely used source of exposure data in ecological studies designed to generate hypotheses relating diet and disease. Their advantage is that they provide standardized estimates of the average amount of food supply for most countries and large contrasts in food consumption patterns among countries (Willett, 1998b). As they are published annually, they also permit time trend analysis. For the majority of countries in the world, FAO food supply data are the only source of information on a country's estimated dietary patterns. Knowing how food availability data reflect food intakes thus becomes a major issue when one wants to estimate the worldwide burden of disease due to inadequate diet or to monitor the effect of health promotion measures.

The results of the present study, based on data from fifteen countries of the Americas, Europe, Asia and the Western Pacific, suggest that while food availability statistics generally tend to overestimate national estimates of fruit and vegetable consumption derived from survey data, the level of discrepancy between the two sources of information varies considerably among countries, both within and between regions. Due to the small number of countries included in the analysis and the limitations of the data used, it is not possible, however, to quantify precisely in true level of discrepancy for a given country. The estimates provided should thus be treated with caution.

The general tendency for FAO food balance sheet data to overestimate national intakes of fruits and vegetables was expected, as food balance sheets reflect national food availability patterns rather than actual dietary intake and thus include both intake and wastage at the retail, foodservice and household levels (Kantor et al. 1997). As a result, they tend to overestimate intakes, particularly in developed market economies (Food and Agriculture Organization, 1983; Sekula et al. 1991; Joffe \& Robertson, 2001). In the European Union, for example, a recent study reported that food balance sheet data overestimated fruit and vegetable consumption by approximately $30 \%$ (Joffe \& Robertson, 2001). The current study yielded a slightly higher estimate based on four European Union countries (Belgium, Denmark, Finland, Italy), with a median difference of $49 \%$. More generally, the overall median discrepancy between FAO and survey data based on the fifteen countries studied was $+39 \%$. Although these findings tend to agree, they hide a wide range of discrepancies which would make it difficult to predict the difference between FAO and survey data for any given country based on its geographic location or level of economic development. For example, in an economically developed country such as Finland, estimates of mean national fruit and vegetable intakes derived from the 1997 Dietary Survey of Finnish Adults (Findiet Study Group, 1998) are relatively high (almost as high as Italy and greater than international recommendations) and slightly higher or at least similar to FAO data; data from the 1992 survey had also showed similarly high intakes (Valsta, 1999). There are several possible explanations for these results. Recent public health campaigns that took place in Finland (Puska, 2000), coupled with changes in the retail trade, and thus in marketing and distribution of fruits and vegetables, may have helped improve dietary habits and increased the fruit and vegetable intake of Finnish people (in this case, intakes were high in spite of the fact that the survey took place in the winter). This would be consistent with the striking improvements in cardiovascular mortality in that country. Alternatively, reported consumption could be inflated by conscious (social desirability bias) or unconscious over-reporting of fruit and vegetable intake by the survey respondents (Hebert et al. 1995). Finally, FAO data could be underestimates due to unmeasured consumption of home-grown foods or incomplete ascertainment of trade flows. Further research is needed to verify these possibilities in Finland, but the importance of home-grown foods in some regions of the former Soviet Union has been reported in the past (Rose \& Tikhomirov, 1993; Rokx et al. 2000). This might partly explain why the overestimation of intakes by FAO data appears to be more moderate in most countries of the former Soviet Union, except the Russian Federation, than in countries of western Europe (except Finland). Availability data might underestimate the total amount of foods available for consumption, thus reducing the difference between food supply and survey estimates. The higher ratio observed in the Russian Federation compared with the Baltic countries may have been due to artificially increased intakes in the later reflecting the fact that the Baltic nutrition surveys were conducted in the summer, a period of increased fruits and vegetables availability and accessibility, with increased likelihood of home-food growing.

The largest differences between food availability statistics and estimated national fruit and vegetable intakes were observed in the USA and Israel. In these countries, FAO data were more than twice as high as survey results. This could suggest, among others, that there is a high level of waste at the retail, foodservice and consumer level. In the USA, it has been estimated that such food losses are equivalent to approximately $23-25 \%$ of the amount of fruits and vegetables available for consumption, after excluding non-edible food parts such as skins, pits, cores and seeds (about $5-30 \%$ of foods). However, this does not fully explain the large discrepancy observed in the present study, suggesting that other factors have taken place, including potential under-reporting of dietary intake, which has been reported in women who participated in the 1994-1996 US Department of Agriculture Continuing Survey of Food Intakes of Individuals (Harrison et al. 2000). In Mediterranean countries such as Israel, it is acknowledged that fruit and vegetable intakes are generally high (Trichopoulou \& Lagiou, 1997). The high discrepancy between FAO and survey data in the present study thus suggests that mean national intakes of fruits and vegetables may have been underestimated due to difficulties in estimating dietary intakes (particularly if family meals are consumed from common serving plates) or potential conscious or unconscious under-reporting of intakes. Conversely, possible inaccuracies in some of the estimates required for the calculation of food balance sheet statistics 
or difficulties in the distribution of foods could have artificially inflated true availability, although no information is available to verity this. In another Mediterranean country, Italy, the overestimation of fruit and vegetable intakes by FAO data is also high but considerably less than for Israel. However, it is greater than that previously estimated for the 1980-4 period (29\% overestimation; Cialfa et al. 1991).

The comparisons described in the present paper are subject to a number of caveats, some of these have been mentioned earlier. A summary is provided in Table 3. First, the validity of food balance sheet statistics depends on the availability and validity of the basic national data on which they are based, including statistics of population, production, stock, import, and export. These are known to vary among countries, and from one year to another, both in terms of coverage and accuracy (Kelly et al. 1991). It has been reported that the estimation of the net availability of vegetables is complicated in many countries by factors, such as non-commercial production and uncertain losses to animal feed, spoilage and waste. However, the FAO performs external consistency checking using supplementary information such as household survey results, as well as the application of relevant technical, nutritional and economic expertise, in an attempt to eliminate these potential deficiencies. In the present study we have used at least 3 years of FAO data to reduce the effect of potential annual variations in coverage and accuracy. Another potential limitation of the data is related to the validity and representativeness of the survey data used and more generally to the difficulties of collecting food intake data. These include the inherent difficulties in measuring dietary intake (Nelson \& Bingham, 1997; Johansson et al. 2001) and the limitations of the various computerized food analysis software used. It is also possible that the survey respondents were not entirely representative of the reference populations, although we attempted to exclude data that were not from nationally representative surveys. In addition, it is important to note that some surveys were conducted at a time of year that may not be representative of annual intakes. In addition, the extrapolations made to estimate national mean intakes based on survey data, particularly when intakes of young children and the elderly had to be assumed, may have caused some over- or underestimations of the overall mean intakes in some countries. Finally, the estimates provided represent mean national intakes that do not take account of variations in intakes among individual within countries.

In conclusion, the present study showed that the level of discrepancy between ecological and individual data on fruit and vegetable consumption varied greatly among the fifteen countries included in the analysis. Although food availability values tended to overestimate national fruit and vegetable intake in all but one country, the range of overestimation level was large, with some values being much higher than expected. Since in most countries food supply statistics are the only source of information on fruit and vegetable intake and more generally dietary patterns, further information is needed on how they reflect actual food intakes. This is particularly important in developing countries where dietary surveys of representative national samples of the populations have been scarce

Table 3. Some potential sources of error which may either increase or decrease the apparent discrepancy between the food availability statistics and survey estimates

\begin{tabular}{|c|c|c|c|}
\hline & \multicolumn{3}{|c|}{ Effect on the discrepancy between food availability statistics and survey estimates } \\
\hline & Either increase or decrease & Increase & Decrease \\
\hline \multirow[t]{2}{*}{$\begin{array}{l}\text { Food availability } \\
\text { statistics }\end{array}$} & $\begin{array}{l}\text { Errors in the estimates } \\
\text { required for the calculation } \\
\text { of food balance sheet } \\
\text { statistics (e.g. trade flows, } \\
\text { population estimates, } \\
\text { uncertain losses to animals, } \\
\text { spoilage, waste, etc.) }\end{array}$ & $\begin{array}{l}\text { Poor distribution of foods } \\
\text { in the country }\end{array}$ & $\begin{array}{l}\text { Non-commercial production } \\
\text { (including home-grown } \\
\text { foods) }\end{array}$ \\
\hline & $\begin{array}{l}\text { Annual variations in the } \\
\text { estimates required for the } \\
\text { calculations }\end{array}$ & $\begin{array}{l}\text { High waste at the retail, foodservice } \\
\text { or consumer levels }\end{array}$ & \\
\hline \multirow[t]{4}{*}{$\begin{array}{l}\text { National estimates } \\
\text { based on } \\
\text { survey data }\end{array}$} & Survey sample not representative & $\begin{array}{l}\text { Survey conducted when availability } \\
\text { and accessibility are low (e.g. winter) }\end{array}$ & $\begin{array}{l}\text { Survey conducted when } \\
\text { availability and } \\
\text { accessibility are high } \\
\text { (e.g. summer) }\end{array}$ \\
\hline & $\begin{array}{l}\text { Limitations of the data } \\
\text { collection method used }\end{array}$ & $\begin{array}{l}\text { Conscious or unconscious under-reporting } \\
\text { of intakes }\end{array}$ & $\begin{array}{l}\text { Conscious or unconscious } \\
\text { over-reporting } \\
\text { of intakes }\end{array}$ \\
\hline & $\begin{array}{l}\text { Limitations of the food } \\
\text { analysis software }\end{array}$ & & \\
\hline & $\begin{array}{l}\text { Bias due to the } \\
\text { extrapolations made in the } \\
\text { present study to obtain } \\
\text { national estimates }\end{array}$ & & \\
\hline
\end{tabular}


in the past. Obtaining precise and valid estimates of dietary intakes in more countries around the world is essential to enable such comparisons. It would help epidemiologists to acquire a better understanding of how differences in dietary intake could play a role in explaining health differences, and is essential for policymakers trying to tackle the rise in non-communicable diseases worldwide.

\section{Acknowledgements}

We would like to acknowledge the contribution of Dr A. Robertson (WHO Regional Office for Europe), and thank K. Baghurst and S. Record (CSIRO Health Sciences \& Nutrition, Adelaide, Australia), S. De Henauw (Department of Public Health, University of Ghent, Belgium), S. Petrova (National Centre of Hygiene, Medical Ecology and Nutrition Sofia, Bulgaria), S. Fagt (Veterinary and Food Administration, Søborg, Denmark), M. Lahti Koski (National Public Health Institute, Helsinki, Finland), D. Nitzan Kaluski and R. Goldberg (Ministry of Health, State of Israel), A. Turrini (Instituto Nazionale di Ricerca per gli Alimenti e la Nutrizione, Rome, Italy), Y. Matsumura and N. Yoshiike (National Institute of Health and Nutrition, Tokyo, Japan), T. Sharmanov (Institute of Nutrition, Republic of Kazakhstan), J. S. Hampl (Department of Nutrition, Arizona State University, USA), B. M. Popkin (North Carolina Population Center, University of North Carolina at Chapel Hill, USA) for providing us with data stratified according to the GBD age and gender categories. This work was supported by a grant from the England Department of Health. However, the England Department of Health cannot accept responsibility for any information provided or views expressed.

\section{References}

Andersen NL, Fagt S, Groth MV, Hartkopp HB, Møller A, Ovesen L \& Warming DL (1996) Danskernes Kostvaner 1995 (The Danes eating habits) Copenhagen: National Food Agency. (In Danish with English Summary.)

Australian Bureau of Statistics (1999) National Nutrition Survey: Foods Eaten, Australia 1995. Canberra: Australian Bureau of Statistics.

Bingham SA, Nelson M, Paul AA, Haraldsdottir J, Løken EB \& Van Staveren WA (1988) Methods of data collection at an individual level. In Manual on Methodology for Food Consumption Studies, pp. 53-106 [ME Cameron and WA van Staveren, editors]. Oxford: Oxford University Press.

Carolina Population Center at the University of North Carolina at Chapel Hill (2001) The China Health and Nutrition Survey. Chapen Hill: Carolina Population Center at the University of North Carolina. http://www.cpc.unc.edu/projects/china/ china_home.html

Carolina Population Center at the University of North Carolina at Chapel Hill (2002) Russia Longitudinal Monitoring Survey. Chapen Hill: Carolina Population Center at the University of North Carolina. http://www.cpc.unc.edu/projects/rlms/ rlms_home.html

Cialfa E, Turrini A \& Lintas C (1991) A national food survey. Food balance sheets and other methodologies: a critical overview. In Monitoring Dietary Intakes, pp. 24-44 [I Macdonald, editor]. Berlin, Germany: Springer-Verlag.

De Henauw S \& De Backer G (1999) Nutrient and food intakes in selected subgroups of Belgian adults. British Journal of Nutrition 81, Suppl. 2, S37-S42.

Department of Economic and Social Affairs (1998) World Population Prospects: The 1998 Revision. New York: United Nations.

Du S, Lu B, Zhai F \& Popkin BM (2002) A new stage of the nutrition transition in China. Public Health Nutrition 5, 169-174.

Ezzati M, Lopez AD, Rodgers A, Vander Hoorn S, Murray CJL \& Comparative Risk Assessment Collaborating Group (2002) Selected major risk factors and global and regional burden of disease. Lancet 360, 1347-1360.

Findiet Study Group (1998) Dietary Survey of Finnish Adults 1997. Helsinki: National Public Health Institute.

Food and Agriculture Organization (1983) A Comparative Study of Food Consumption Data From Food Balance Sheets and Household Surveys. Rome: FAO.

Food and Agriculture Organization (1998a) Nutrition Country Profile: Nepal. Rome: FAO.

Food and Agriculture Organization (1998b) Nutrition Country Profile: Pakistan. Rome: FAO.

Food and Agriculture Organization (2002) FAOSTAT database. http://apps.fao.org/1

Food and Agriculture Organization/World Health Organization/ United Nations University (1985) Energy and Protein Requirements. Report of a Joint FAO/WHO/UNU Expert Consultation. Technical Report Series no. 724. Geneva: WHO.

Harrison GG, Galal OM, Ibrahim N, Khorshid A, Stormer A, Leslie J \& Taha Saleh N (2000) Underreporting of food intake by dietary recall is not universal: a comparison of data from Egyptian and American women. Journal of Nutrition 130, 2049-2054.

Hebert JR, Clemow L, Pbert L, Ockene IS \& Ockene JK (1995) Social desirability bias in dietary self-report may compromise the validity of dietary intake measures. International Journal of Epidemiology 24, 389-398.

Joffe M \& Robertson A (2001) The potential contribution of increased vegetable and fruit consumption to health gain in the European Union. Public Health Nutrition 4, 893-901.

Johansson G, Wikman A, Ahren AM, Hallmans G \& Johansson I (2001) Underreporting of energy intake in repeated 24-hour recalls related to gender, age, weight status, day of interview, educational level, reported food intake, smoking habits and area of living. Public Health Nutrition 4, 919-927.

Kantor LS, Kipton K, Manchester A \& Oliveria V (1997) Estimating and addressing America's food losses. In Food Review. Washington, DC: US Department of Agriculture, Economic Research Service.

Kelly A, Becker W \& Helsing E (1991) Food balance sheets. In Food and Health Data. Their Use in Nutrition Policymaking. WHO Regional Publications, European Series no. 34, pp. 39-48 [W Becker and E Helsing, editors]. Copenhagen: WHO Regional Office for Europe.

Klerk M, Jansen MCJF, van't Veer P \& Kok FJ (1998) Fruits and Vegetables in Chronic Disease Prevention. Part II: Update and Extension (Literature up to Early 1998). Wageningen: Wageningen Agricultural University.

Lagiou P, Trichopoulou A, Henderickx HK, Kelleher C, Leonhauser IU, Moreiras O, Nelson M, Schmitt A, Sekula W, Trygg K \& Zajkas G (1999) Household budget survey nutritional data in relation to mortality from coronary heart disease, colorectal cancer and female breast cancer in European countries. DAFNE I and II projects of the European 
Commission. Data Food Networking. European Journal of Clinical Nutrition 53, 328-332.

Lock K, Pomerleau J, Causer L \& McKee M (2003) Global burden of disease due to low fruit and vegetable consumption. In Comparative Quantification of Health Risks: Global and Regional Burden of Disease Due to Selected Major Risk Factors, [M Ezzati, AD Lopez, A Rodgers and CJL Murray, editors]. Geneva: WHO (In the Press).

Ministry of Health and Welfare (2000) Annual Report of the National Nutrition Survey in 1998. Tokyo: Daiichi Publishing Co.

Mizushima S (2001) National Nutrition Survey. Tokyo: The University of Tokyo.

National Institute of Nutrition of Kazakhstan and Macro International Inc. (1996) Kazakhstan Demographic and Health Survey, 1995. Calverton, MD: National Institute of Nutrition and Macro International Inc.

Nelson M \& Bingham SA (1997) Assessment of food consumption and nutrient intake. In Design Concepts in Nutritional Epidemiology, 2nd ed. pp. , 123-169 [BM Margetts and M Nelson, editors]. Oxford: Oxford University Press.

Petrova S (1998) National dietary and nutritional status survey of the population in Bulgaria, 1998. Food consumption. Hygiene and Public Health XLIII, 55-62.

Pomerleau J, McKee M, Robertson A, Vaask S, Pudule I, Grinberga D, Kadziauskiene K, Abaravicius A \& Bartkeviciute $\mathrm{R}$ (2000) Nutrition and Lifestyle in the Baltic Republic. PHP Departmental Publication no. 32. London: London School of Hygiene and Tropical Medicine.

Puska P (2000) Nutrition and mortality: the Finnish experience. Acta Cardiologica 55, 213-220.

Rokx C, Galloway R \& Brown L (2000) Prospects for Improving the Nutrition Situation in Eastern Europe and Central Asia. New York: World Bank.

Rose R \& Tikhomirov Y (1993) Who grows food in Russia and eastern Europe? Post Soviet Geography 34, 111-126.

Sekula W, Becker W, Trichopoulou A \& Zajkas G (1991) Comparison of dietary data from different sources: some examples. In Food and Health Data. Their Use in Nutrition Policy-making. WHO Regional Publications, European Series no. 34, pp. 91-117 [W Becker and E Helsing, editors]. Copenhagen: WHO Regional Office for Europe.

Statistics Division (1983) A Comparative Study of Food
Consumption Data from Food Balance Sheets and Household Surveys. FAO Economic and Development Paper. Rome: Food and Agriculture Organization.

Tippett KS \& Cypel YS (editor) (1997) Design and Operation: The Continuing Survey of Food Intakes by Individuals and the Diet and Health Knowledge Survey, 1994-96. NFS Report no. 96-1, (editor). Washington, DC: US Department of Agriculture, Agriculture Research Service.

Trichopoulou A \& Lagiou P (1997) Healthy traditional Mediterranean diet: an expression of culture, history, and lifestyle. Nutrition Reviews 55, 383-389.

Turrini A, Leclercq C \& D'Amicis A (1999) Patterns of foods and nutrient intakes in Italy and their application to the development of food-based dietary guidelines. British Journal of Nutrition 81, Suppl. 2, 83-89.

Turrini A, Saba A, Perrone D, Cialfa E \& D'Amicis A (2001) Food consumption patterns in Italy: the INN-CA Study 1994-1996. European Journal of Clinical Nutrition 55, $571-588$

Valsta LM (1999) Food-based dietary guidelines for Finland - a staged approach. British Journal of Nutrition 81 Suppl. 2, S49-S55.

Volatier JL (1999) Enquête Individuelle et Nationale sur les Consommations Alimentaires (National Individual Food Consumption Survey). Paris: Editions TEC et DOC.

Willett W (editor) (1998a) Nutritional Epidemiology. Oxford: Oxford University Press.

Willett W (1998b) Overview of nutritional epidemiology. In Nutritional Epidemiology, 2nd ed. pp. 3-17 [W Willett, editor]. New York: Oxford University Press.

World Cancer Research Fund \& American Institute for Cancer Research (1997) Food, Nutrition and the Prevention of Cancer: A Global Perspective. Washington, DC: American Institute for Cancer Research.

World Health Organization (1990) Diet, Nutrition and the Prevention of Chronic Diseases. Report of a WHO Study Group Technical Report Series no. 797. Geneva: WHO.

World Health Organization (2002a) World Health Organization Process for a Global Strategy on Diet, Physical Activity and Health. Geneva: WHO.

World Health Organization (2002b) The World Health Report 2002. Reducing Risks, Promoting Healthy life. Geneva: WHO. 